


\title{
MILK PRODUCTION AND MODIFICATION OF MILK FATTY ACID OF DAIRY COWS FED PUFA-CONCENTRATE
}

\author{
E. Sulistyowati, U. Santoso and I. Badarina \\ Animal Science Department, Faculty of Agriculture, University of Bengkulu \\ Jl. Raya W.R. Supratman- Bengkulu 38371- Indonesia \\ Corresponding E-mail: Ensulistyowati@yahoo.com
}

Received October 28, 2010; Accepted November 26, 2010

\begin{abstract}
Some fatty acid supplements in concentrate containing Curcuma xanthorrhiza, ROXB were evaluated for effects on milk yield, milk fat and protein, including milk fatty acid. Four lactating ( $4 \pm 1.5$ months ) Fries Holland (FH) cows were allocated into four treatments of concentrate containing 4.5\% palm oil (CP0), $4.5 \%$ corn oil (CP1), $4.5 \%$ roasted ground corn (CP2), and $1.5 \%$ corn oil and $3 \%$ roasted ground corn (CP3), respectively, in $4 \times 4$ Latin Square experimental design with 3 d-period. Results showed that there were no significant $(\mathrm{P}>0.05)$ effects on milk yield, milk fat and protein, and milk fatty acid. However, the highest average of milk production was found in CP2 $(8.63 \mathrm{~kg} / \mathrm{d})$. Milk fat was decreasing to $3.81 \%$ in conjunction with the more potential total PUFA $(71.81 \%)$ in CP3 with corn oil and roasted ground corn. Ratio of omega- 6 to omega- 3 in milk was the same in both, CP2 and CP3, it was 2.14. However, since the objective of this research was to improve milk yield as well as milk components and health concern, therefore the CP2 with roasted ground corn was considered as the optimal one.
\end{abstract}

Keywords: Milk production, milk fatty acid, PUFA- concentrate

\section{INTRODUCTION}

Milk production nationally provides only about $30 \%$ (636,900 ton) out of national milk demand. Not only the quantity, but the quality, such as milk fatty acids (omega-9, omega-6, and omega-3), needs improvement for healthier reason, meaning higher omega- 3 or decreasing $n$ 6/n-3 ratio to about 2 (Petit, 2003 and Cortes et al., 2010). However, there has been a wide variation in the market for milk product with the ratio of omega- 6 to omega -3 at about 6.7- 18.1 in liquid milk (Beare- Rogers, 1989) and 9-11.7 in formula milk (Carlson, 1989). Concentrate containing C. xanthorrhiza, Roxb with palm oil, corn oil, roasted ground corn, and combination of corn oil and roasted ground corn was one effort to meet these requirements. The concentrate with $C$. xanthorrhiza, Roxb has been approved to increase milk production in dairy cows (Sulistyowati et al., 2010). Addition of fat including fatty acid source are not only as energy source but as biological modifier in metabolism. Polyunsaturated fatty acids (PUFA) is incompletely bio hydrogenised in duodenum that will increase C18:1 and conjugated linoleic acid (CLA), which has been then associated with decreasing milk fat (Bauman and Griinari, 2003). The altering fatty acid would affect the composition of the fatty acids in livestock products, such as milk. Concentrations of C18:1n-9, C18:2n-9, and C18:3n-3 were increased in milk fat from cows fed with flaxseed oil and its combination with whole flaxseed as reported by Cortes et al. (2010).

The objective of this experiment was to determine the effects of fatty acid sources of palm oil, corn oil, roasted ground corn, and the mix of corn oil and roasted ground corn on milk production, milk fat, milk fatty acids, and ratio of omega- 6 to omega-3 in dairy cows.

\section{MATERIALS AND METHODS}

\section{Cows and Treatments}

Four lactating dairy cows with specification of $4 \pm 1.5$ months of lactation, $8.06 \pm 0.7 \mathrm{~kg}$ of milk production, and $402.50 \pm 32.57 \mathrm{~kg}$ of body weight were used in this study. These cows were kept by farmers in Selupu Rejang, Bengkulu, Indonesia, and assigned randomly in $4 \times 4$ Latin Square arrangement of treatments. The four treatments were concentrate containing $15 \mathrm{~g}$ C. xanthorrhiza, 
$\mathrm{ROXB} / \mathrm{kg}$ concentrate with $4.5 \%$ palm oil (CP0), $4.5 \%$ corn oil (CP1), $4.5 \%$ roasted ground corn (CP2), and the mix of $1.5 \%$ corn oil and $3 \%$ roasted ground corn (CP3). This PUFAconcentrate was provided as much as $3 \mathrm{~kg} / \mathrm{d}$ portioned in morning and afternoon feeding each day. Treatment diets are shown in Table 1.

\section{Data and Sample Collection}

Cows were housed in individual stalls, fed with grass and concentrate twice a day, mornings (06.00) and afternoon (15.00). Amount of feed offered and orts were weighed daily for each cow. Samples of diets were collected in day 18 to 21 each period for determining chemical composition by proxymate analysis. Cows were milked once in the morning. Milk yield was measured and recorded daily. Milk samples were taken during the last two consecutive milking for each period.

\section{Sample and Statistical Analysis}

Feed samples were handled and analyzed for nutrients by proxymate method. Milk samples were assessed for milk fat and milk protein, while milk fatty acids were assayed for saturated and unsaturated fats.

Data were tabulated to see the average and variation of each cow, each treatment in each period. Analysis of variance was calculated based on reference of Lentner and Bishop (1986) utilizing Costat program.

\section{RESULTS AND DISCUSSION}

\section{Nutrient Content of Diets}

Nutrient content of control and treated diets used in this experiment was showing relatively similar among the treatments (Table 2). However, concentrate with $4.5 \%$ roasted ground corn (CP2) was having the lowest crude protein $(11.36 \%)$ and lowest ether extract $(0.41 \%)$, yet the highest crude fiber $(2.31 \%)$. The protein content in this research was lower compared to that of in the previous concentrate $(17.72 \%)$ containing the same level of C. xanthorrhiza, Roxb (15 g/kg concentrate) but with different level of urea $(7 \%)$ and different level of palm oil $(1.5 \%)$. The contents of crude fiber was higher $(7.96 \%)$, while the ether extract content was relatively lower $(0.34 \%)$ in that concentrate as reported by Sulistyowati et al. (2010). The lowest crude fat or ether extract found in this study was a reflection of the concentrate with no oil resource instead of roasted ground corn (CP2). This is in conjunction with the lipogenic diet containing $0.025 \%$ palm oil, resulting in about $72.2 \%$ higher in its crude fat

Table 1. Composition of Concentrate of Experimental Diets in Lactating Dairy Cows

\begin{tabular}{|c|c|c|c|c|}
\hline \multirow{2}{*}{ Ingredients } & $\mathrm{CP0}$ & $\mathrm{CP} 1$ & $\mathrm{CP} 2$ & $\mathrm{CP} 3$ \\
\hline & \multicolumn{4}{|c|}{----- \% DM---- } \\
\hline Rice hulls & 60 & 60 & 60 & 60 \\
\hline Ground corn & 12 & 12 & 12 & 12 \\
\hline Cassava meal & 10 & 10 & 10 & 10 \\
\hline $\mathrm{NaCl}$ & 2 & 2 & 2 & 2 \\
\hline $\mathrm{CaCO} 3$ & 2 & 2 & 2 & 2 \\
\hline TSP & 1 & 1 & 1 & 1 \\
\hline Urea & 4 & 4 & 4 & 4 \\
\hline Starbio & 1 & 1 & 1 & 1 \\
\hline Yeast & 0.5 & 0.5 & 0.5 & 0.5 \\
\hline Palm sugar & 2 & 2 & 2 & 2 \\
\hline Palm oil & 4.5 & - & - & - \\
\hline Corn oil & - & 4.5 & - & - \\
\hline Roasted ground corn & - & - & 4.5 & - \\
\hline $1.5 \%$ Corn oil and $3 \%$ Roasted ground corn & - & - & - & 4.5 \\
\hline Total & & 100 & 100 & 100 \\
\hline C. xanthorrhiza (g/kg CP) & 15 & 15 & 15 & 15 \\
\hline
\end{tabular}


Table 2. Nutrient Content of Diets Applied in Lactating Dairy Cows

\begin{tabular}{|c|c|c|c|c|}
\hline \multirow{2}{*}{ Content } & $\mathrm{CP0}$ & $\mathrm{CP} 1$ & $\mathrm{CP} 2$ & $\mathrm{CP} 3$ \\
\hline & \multicolumn{4}{|c|}{----- Nutrient $(\%)$------ } \\
\hline Dry matter (DM) & 86.24 & 87.45 & 87.96 & 88.02 \\
\hline Crude protein $(\mathrm{CP})$ & 12.35 & 12.01 & 11.36 & 12.98 \\
\hline Crude fiber & 1.96 & 2.02 & 2.31 & 2.22 \\
\hline Ether Extract (EE) & 0.45 & 0.52 & 0.41 & 0.55 \\
\hline Gross Energy (GE) (Mcal) & 2.36 & 2.55 & 2.46 & 2.39 \\
\hline
\end{tabular}

CP0 : palm oil $4.5 \%, \quad$ CP1: corn oil $4.5 \%, \quad$ CP2: roasted ground corn $4.5 \%$; and CP3: corn oil $1.5 \%$ and roasted ground corn $3 \%$.

compared to that of in the glucogenic diet (no fat source) as reported by van Knegsel et al (2007). While, the energy content provided in corn oil concentrate (CP1) was being the highest compared to roasted ground corn concentrate (CP2) and mix concentrate (CP3).

\section{Concentrate Fatty Acid Profile}

The fatty acids from plant (palm and corn) oils were specific. In the average level, palm oil was relatively high in omega-9 and omega-3, while corn oil was higher in omega-6, as presented in Table 3.

In general, the total PUFA (C18:1 n-9 through C22:6n-3) found being the highest was in CP0- palm oil $(79.19 \%)$ then secondly was in CP2- roasted ground corn $(78.64 \%)$. The palm oil was higher in omega-9 and omega- 3, while its ratio of omega- 6 to omega-3 was the lowest (1.52). Since all the ratios of these concentrates were in the range of 1.5-2.0, it has an implication of better nutritive value. Another ratio, PUFA/Saturated fatty acid (P/S) among the diets, as the contents of PUFA was the highest and saturated fat being the lowest, therefore its ratio was found being the highest in palm oil concentrate (3.25). As comparison, in diets containing saturated fat (prilled hydrogenated fat) and unsaturated fat (Ca soaps of long chain fatty acid), the ratio of $\mathrm{P} / \mathrm{S}$ were 0.88 and 1.69, respectively (Harvatine and Allen, 2006). These suggested that the type of fat supplemented in concentrate would determine its type of fatty acid. Meanwhile, in flaxseed containing concentrate, both treated and untreated with formaldehyde was

Table 3. Fatty Acids Profile of PUFA-concentrate

\begin{tabular}{lrrrr}
\hline \multicolumn{1}{c}{ Fatty acid (\% total fat) } & CP0 & CP1 & CP2 & CP3 \\
\hline Palmitate: C16:0 & 15.16 & 16.21 & 15.86 & 15.65 \\
Stearate: C18:0 & 9.24 & 9.68 & 10.05 & 9.48 \\
Total saturated fatty acid & 24.4 & 25.89 & 25.91 & 25.13 \\
Oleat : C18:1n-9 & 48.32 & 47.52 & 48.26 & 47.27 \\
Linoleate : C18:2n-6 & 18.62 & 19.04 & 18.64 & 18.54 \\
Linolenate : C18:3n-3 & 8.57 & 8.12 & 8.44 & 8.36 \\
Eicosapentaenoate : C20:5n3 & 1.28 & 1.04 & 1.12 & 1.08 \\
Decosapentaenoate : C22:5n-3 & 1.06 & 0.82 & 1.02 & 0.94 \\
Decosahexaenoate: C22:6n-3 & 1.34 & 0.96 & 1.16 & 1.04 \\
Total PUFA (C18:1 n-9 through C22:6n-3) & 79.19 & 77.5 & 78.64 & 77.23 \\
Ratio PUFA/Saturated (P/S) & 3.25 & 2.99 & 3.04 & 3.07 \\
Ratio omega-6/omega-3 & 1.52 & 1.74 & 1.59 & 1.62 \\
\hline CP0 : palm oil 4.5\%, CP1: corn oil 4.5\%, CP2: roasted ground corn 4.5\%; and CP3: \\
corn oil 1.5\% and roasted ground corn 3\%.
\end{tabular}


showing moderate amount of C18:1 and high in C18:3. While, in sun flower containing concentrate, both treated and untreated, C18:2 was found being the highest (Petit, 2003). This would suggest that formaldehyde was not effective enough to protect polyunsaturated fatty acids against ruminal biohydrogenation.

\section{Milk Production, Milk Components, and Dry Matter Intake}

Fatty acid supplements did not affect milk yield of the lactating dairy cows fed with concentrate containing $C$. xanthorrhiza, Roxb. However, milk yield was linearly decreased in the oil containing diets-CP0, CP1, and CP3. The milk fats were decreasing all the way from diets with palm oil (CP0), corn oil (CP1), ground corn (CP2), and mix corn oil- ground corn (CP3) as shown in Table 4.

Milk yields showed no significant differences $(\mathrm{P}>0.05)$ for cows among treatments, however there was in CP2-roasted ground corn that showed the highest one $(8.63 \mathrm{~kg} / \mathrm{d})$. It is about $0.60 \mathrm{~kg} / \mathrm{d}$ difference over CP1- palm oil, or about $7.5 \%$ increase. The highest milk yield was supported by the highest dry matter intake $(13.05 \mathrm{~kg} / \mathrm{d})$ showed in CP2-roasted ground corn. The milk yield was then decreased in $\mathrm{CP} 3$ that contained more potential PUFA from the combination of corn oil and roasted. The same fact happened in unsaturated fatty acid supplementation that its milk yield was being the lowest (43.7 $\mathrm{kg} / \mathrm{d}$ ) compared to that of in control (47.0 $\mathrm{kg} / \mathrm{d}$ ) as reported by Harvatine and Allen (2006). This is true that milk yield was linearly decreased with increasing unsaturated fatty acids. Increasing unsaturated fatty acid supplement linearly decreased milk fat, from $3.94 \%$ in CP0-palm oil to $3.81 \%$ in $\mathrm{CP} 3$-corn oil and roasted ground corn. This trend was also happened with $4 \%$ FCM. So far, the similar pattern found in milk fat of saturated fatty acid $(1.37 \%)$ and unsaturated fatty acid supplement $(1.10 \%)$ as reported by Harvatine and Allen (2006). The synthesis of milk fat is blocked by fatty acids intermediates resulted from biohydrogenation of unsaturated fatty acid in rumen and milk fat depression is linked to higher PUFA diets as described by Bauman and Griinari (2003). It means that fatty acid supplements in the concentrate did not affect biosynthesis of protein into milk, as it happened in with the supplementation of saturated, intermediate unsaturated, and $\mathrm{Ca}$ soap of long chain fatty acid supplementation did not affect significantly on milk protein (2.88-2.96\%), as reported by Harvatine and Allend (2006).

\section{Milk Fatty Acid Profile}

The total milk fatty acid showed that the saturated fatty acid were $26.95-30.32 \%$ while the unsaturated fatty acid were $61.96-71.81 \%$. Table 5 shows the fatty acid profile among the treatments.

The PUFA composition in milk (C18:1n-9 through C22:6n-3) found the highest $(71.81 \%)$ was in CP3- corn oil and roasted ground corn, while the lowest $(61.96 \%)$ was in CP2- roasted ground corn. Processing of feed containing fatty acid, is an effort to improve the content of its fatty acid, especially the PUFA. Roasted soybean in $115{ }^{\circ} \mathrm{C}$ resulted in higher fatty acids of $\mathrm{C} 18: 1$

Table 4. Milk Production, Milk Components and Dry Matter Intake of Dairy Cow s Fed PUFA-concentrate

\begin{tabular}{lcccc}
\hline \multicolumn{1}{c}{ Fatty acid (\% total fat) } & CP0 & CP1 & CP2 & CP3 \\
\hline Milk Production $(\mathrm{kg} / \mathrm{d})$ & 8.03 & 8.49 & 8.63 & 8.38 \\
- Milk fat $(\%)$ & 3.94 & 3.86 & 3.84 & 3.81 \\
- 4\% FCM & 7.95 & 8.24 & 8.42 & 8.15 \\
- Milk Protein $(\%)$ & 3.59 & 3.74 & 3.70 & 3.75 \\
Dry matter intake $(\mathrm{kg} / \mathrm{d})$ & 12.99 & 12.93 & 13.05 & 12.98 \\
\hline
\end{tabular}

No significant differences $(\mathrm{p}>0.05)$ among treatments. CP0 : 4,5\% palm oil, CP1: $4,5 \%$ corn oil, $\mathrm{CP} 2$ : $4,5 \%$ roasted ground corn; and CP3: $1,5 \%$ corn oil and $3 \%$ roasted ground corn. 
Table 5. Milk Fatty Acid Profile of Dairy Cows with PUFA-concentrate

\begin{tabular}{lrrrr}
\hline \multicolumn{1}{c}{ Fatty acid } & CP0 & CP1 & CP2 & CP3 \\
\hline Palmitate: C16:0 (\%) & 22.06 & 20.56 & 21.67 & 21.56 \\
Stearate : C18: 0 (\%) & 7.43 & 6.39 & 8.85 & 7.04 \\
Sub total Saturated & 29.49 & 26.95 & 30.52 & 28.6 \\
Oleat : C18:1n-9 (\%) & 31.17 & 27.24 & 27.39 & 30.52 \\
Linoleate : C18:2n-6 (\%) & 27.33 & 25.34 & 23.57 & 28.12 \\
Linolenate : C18:3 n-3 (\%) & 3.78 & 3.42 & 3.23 & 3.85 \\
Eicosapentaenoate : C20:5n3 (\%) & 2.93 & 2.67 & 2.45 & 2.88 \\
Decosapentaenoate: C22:5n-3 (\%) & 3.45 & 3.43 & 3.01 & 3.32 \\
Decosahexaenoate: C22:6n-3 (\%) & 3.07 & 2.88 & 2.31 & 3.12 \\
Sub total omega-3 & 13.23 & 12.4 & 11.00 & 13.17 \\
Sub total PUFA & 71.73 & 64.98 & 61.96 & 71.81 \\
Ratio P/S & 2.43 & 2.41 & 2.03 & 2.51 \\
Ratio omega-6/omega-3 & 2.07 & 2.04 & 2.14 & 2.14 \\
\hline
\end{tabular}

CP0 : $4.5 \%$ palm oil, $\mathrm{CP} 1: 4.5 \%$ corn oil, $\mathrm{CP} 2: 4.5 \%$ roasted ground corn; and $\mathrm{CP} 3: 1.5 \%$ corn oil and $3 \%$ roasted ground corn

(21.79\%), C18:2 (4.23\%), and $\mathrm{C} 18: 3(0.66 \%)$, and these are better than ground soybean as reported by Chouinard et al (2001). Heating process made the oil comes out later after bypassing rumen bio hydrogenation. However, the result in this study was on the contrary as in the $\mathrm{CP} 2$ with roasted ground corn was being the lowest. This might be due to the different technique that has been used in processing. In our study, the ground corn was roasted manually in $100{ }^{\circ} \mathrm{C}$ for about 45 minutes, until the corn turned light brown.

Concentrations of all PUFA components, omega-9, omega- 6 , and omega-3 were showing similar patterns, starting from the highest in CP0palm oil, then gradually decreasing in CP1-corn oil and CP2-roasted ground corn, it was back increasing in CP3-corn oil and roasted corn oil. In comparison, diet containing $72 \mathrm{~g} / \mathrm{kg}$ DM ground flaxseed contribute to increase lypolisis better than diets with $21 \mathrm{~g} / \mathrm{kg} \mathrm{DM} \mathrm{Ca}$ salt palm oil, 72 $\mathrm{g} / \mathrm{kg}$ DM whole flaxseed and of half of each feed (Petit and Cortes, 2010). Other result was also showing the same trend that feeding flaxseed oil and its mix increased C:18:3 (75\%) compared to that of in diet with no flaxseed (61\%), reported by Cortes et al (2010). Flaxseed products decreased the $\mathrm{n}-6 / \mathrm{n}-3$ ratio in milk fat and supplying about $1 \%$ of fat in the diet would slightly improve the value of the nutrients in milk fat for better human concerns on wellness.

Ratio of milk P/S was found the highest (2.51) in mix concentrate (CP3) while in roasted ground corn concentrate was the lowest (2.03) which coming out from their P/S diets of 3.07 and 3.05 , respectively. This suggested that all the oil containing diets are effective in modifying the content of milk PUFA. This condition supported the result reported by Harvatine and Allen (2006) that increasing unsaturated fatty acid decreased concentration of short and medium- chain fatty acid but increased concentration of some long chain fatty acid.

Ratio of milk omega- 6 to omega-3 (n-6/n-3) was found the same as in both $\mathrm{CP} 2$ - roasted ground corn and CP3- corn oil and roasted ground corn, that was 2.14 , while the lowest ratio was found in CP1- corn oil, that was 2.04. Petit (2003) reported that such ratio in unsaturated flaxseed was found being the lowest (1.7) and the formaldehyde flaxseed oil was about 2.3; while the ratio in sunflower was around 8.3. The higher the level of n-3 of any feed, it would decrease the ratio of $n-6 / n-3$. The implication of the lower ratio of omega- 6 to omega- 3 in milk, is considered as better for health. Therefore, milk from concentrate with corn oil-CP1 was healthier. Since, the goals of this modification of PUFA-concentrate formula were to increase milk production and at the same 
time to improve milk quality, especially its fatty acid content, therefore based on the optimal variables such as milk yield, milk omega6/omega-3, and the availability of the feed in farmers level, it is suggested that concentrate with $4.5 \%$ roasted ground corn $(\mathrm{CP} 2)$ is considerable.

\section{CONCLUSION}

Based on milk production and milk ratio of omega- 6/omega-3 as well as its supply in the market, it has been suggested that PUFAconcentrates containing of $4.5 \%$ roasted ground corn was considered as the optimal formula.

\section{ACKNOWLEDGMENT}

This second year- research has been granted by HIBAH BERSAING - DIKTI with contract no 2235/H30.10.06.01/HK/2010. The authors would like to give appreciation for funding this project.

\section{REFERENCES}

Bauman, D.E., and J. M. Griinari. 2003. Nutritional regulation of milk fat synthesis. Annu. Rev. Nutr. 23:203- 227

Beare-Rogers, J.L. 1989. Some Aspect of Omega3 Fat Acid from different Foods. In Dietary w3 and w6 Fatty Acids. Biologycal Effects and Nutritional Essentiality Plenum. PressNATO. New York-London.

Carlson, S.E. 1989. Polyunsaturated Fatty Acids and Infant Nutrition In: Dietary w3 and w6 Fatty Acids. Biologycal Effects and Nutritional Essentiality Plenum. PressNATO. New York-London.

Chuinard, P. Y., L. Crneau, W. Butler, Y. Chilliard, J. K. Drackley, and D. E. Bauman. 2001. Effect of dietary lipid source on conjugated linoleic acid concentrations on milk fat. J. Dairy Sci. 84: 680-690.

Cortes, C., D.C. da Silva Kazama, R. Kazama, N. Gagnon, C. Benchaar, G.T.D. Santos, L.M. Zeoula, H.V. Petit. 2010. Milk composition, milk fatty acid profile, digestion, and ruminal fermentation in dairy cows fed whole flaxseed and calcium salts of flaxseed oil. J. Dairy Sci. 93: 3146-3157.

Harvatine, K.J. and M.S. Allen. 2006. Effects of fatty acid supplements on milk yield and Energy balance of lactating dairy cows. J. Dairy Sci. 89:1081-1091.

Larson, B.L. 1985. Lactation. The Iowa State University Press. Ames. IA. USA.

Lentner, M and T. Bishop. 1986. Experimental Design and Analysis. Valley Book Co. VA.

Moallem, U., H. Lehrer, L. Livshitz, M. Zachul and S. Yakoby. 2009. The effects of live yeast supplementation to dairy cows during the hot season on production, feed efficiency, and digestibility. J. Dairy Sci. 92:343-351.

Mozzon, M., N. G. Frega, B. Fronte, and M. Tocchini. 2002. Effect of Dietary fish oil supplements on level of n- 3 PUFA, trans CLA in ewe milk. Food Technol. Biotechnol. 40 (3): 213-219.

National Research Council. 1989. Dairy Cattle Requirement. $6^{\text {th }}$ Revised Ed. National Academy Press. Washington, DC.

Petit, H.V. 2003. Digestion, milk production, milk composition, and composition of dairy cows fed formaldehyde treated flaxseed or sunflower seed. J. Dairy Sci. 86:2637- 2646.

Petit, H.V. and C. Cortes. 2010. Milk production and composition, milk fatty acid profile, and blood composition of cows fed whole or ground flaxseed in the first half of lactation. Anim. Feed Sci. and Tech. 158: 36-43.

Sulistyowati, E., I. Badarina, and E. Soetrisno. 2010. Supplementation of Starbio probiotic and yeast on milk production and nutrient digestibility of lactating Holstein cows fed a ration containing cassava meal. J. Dairy Sci. 93. E. Suppl. 1: 859-860.

Sulistyowati, E., U. Santoso, and I. Badarina. 2010. Total digestible nutrient of concentrate lactation with different levels of Curcuma xanthorrhiza, Roxb. JSPI. 5: 20- 26.

Van Knegsel, A.T.M., H. van den Brand, J. Dijkstra, W.M. van Straalen, R. Jorritsma, S. Tamminga, and B. Kemp. 2007. Effect of glucogenic vs lipogenic diets on energy balance, blood metabolites, and reproduction in primiparous and multiparous dairy cows in early lactation. J. Dairy Sci. 90:3397-3409.

Webster- T.M., W. H. Hoover, M. Holt, and J. E. Nocek. 2002. Influence of yeast culture on ruminal microbial metabolism in continuous culture. J. Dairy Sci. 85:2009-2014. 